\title{
EFFECT OF INTEGRATED YOGA PROGRAM ON ENERGY OUTCOMES AS A MEASURE OF PREVENTIVE HEALTH CARE IN HEALTHY PEOPLE
}

\author{
Kuldeep Kumar Kushwah,, B, C, D Hongasandra Ramarao Nagendra,, ${ }^{\text {, D }}$ \\ Thaiyar Madabusi Srinivasan ${ }^{\mathrm{A}, \mathrm{D}}$
}

\author{
S-VYASA University, Bangalore, India

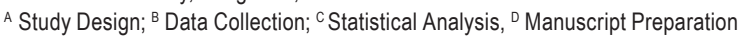 \\ Address for correspondence: \\ Kuldeep Kumar Kushwah, Ph.D. Scholar \\ Swami Vivekananda Yoga Anusandhana Samsthana \\ \# 19, 'Eknath Bhavan', Gavipuram Circle, Kempe Gowda Nagar, Bengaluru - 560 019, India \\ E-mail: kuldeepkush86@gmail.com
}

\begin{abstract}
Ahstract. The aim of this study was to measure the changes in stress, general health index and disorderliness in human energy pattern through Integrated Yoga Practices (IYP). Ninety four healthy volunteers (male 55 and female 39), age (mean $\pm s d 26.70 \pm 8.58$ ) were assessed before and after four weeks of IYP. The experiment was conducted four times and the assessment was done by utilizing the Electro Photonic Imaging (EPI) technique. Comparisons were made to ascertain whether energy homeostasis diverges based on genders. The parameters considered for analysis were Activation Coefficient (AC), Integral Area (IA) and Integral Entropy (IE). Reduction in stress levels (AC), increase in general health index (IA) and decrease in disorderliness (IE) on the left side parameters were found reproducible in all four experiments. The results also revealed a highly significant reduction in stress levels and highly significant improvement in the health indices at the psycho-physiological level. The subgroup analysis of both male and female demonstrated a significant reduction in stress levels and significant improvement in health index (psycho-physiological). Baseline comparisons between males and females showed significant difference in general health index at both psychophysiological and physiological levels. In conclusion, IYP regulates, improves and prolongs energy homeostasis of an organism. Therefore, it helps in prevention of ill health and also preserves health. The EPI outcomes are reproducible. Further, the present study also found that the energy pattern differs with gender. Hence, it is suggested that studies with male and female participants may be conducted separately.
\end{abstract}

Key WOPll:" Integrated Yoga Program IYP, Electro Photonic Imaging Technique EPI, Gas Discharge Visualization GDV, Stress, General Health Index and Disorderliness

\section{Introduction}

Health and its care have become a global concern. The fast pace of life, sedentary lifestyle, immoderation in diet, activities, recreation and sleep are the factors responsible for stressful living which ultimately manifest in diseases (Bijlani et al. 2005; Sivananda 2008a; Smaldone et al. 2007; Waxman 2005) like obesity, diabetes mellitus, heart diseases, hyperlipidaemia, respiratory infections and cancer (Segasothy and Phillips 1999; Sharma and Majumdar 2009). They affect daily work and quality of life of individuals (Van Nieuwenhuizen et al. 2015). 
Thus, there is a need for change in lifestyle in most populations to prevent ill health and promote good health. Since energy is the foundation of electrophysiological and biochemical processes, it is necessary to measure and correlate the energy through available technology known as electro photonic imaging technique (EPI).

Yoga, an ancient Indian lifestyle-related discipline has been scientifically proven and shown to improve physical, mental, and emotional wellbeing (Buffart et al. 2012; Gard et al. 2014) through all its components which include Kriya (cleansing techniques), Asana (yogic postures), Pranayama (breathing practices), Dhyana (meditation) and diet. These techniques correct energy imbalances, and restores energy homeostasis in humans (Lynton at al. 2007). This energy which is subtle known as Prana (Srinivasan 2014). It is considered to be the vital energy that regulates all cellular processes and keeps a person healthy. As per the Ayurvedic texts, Prana (Traditional Chinese Medicine counterpart, Qi), is believed to be responsible for health of every cell in the body (Sancier and Hu 1991). Availability of cellular electrons is closely related to the health of cells (Szent-Gyorgyi 1978). We conceptually tried to relate Prana (the fundamental febric of subtle energy) with electrons (the fundamental aspect of matter) and expect that both will converge closely. Through this, we tried to derive our operational definitions of various abstract constructs. The conceptual relationship between Prana and electrons seems to be quite evident, however, more empirical evidence is needed to support this concept. We operationally define Prana as the intensity of electro photonic emission patterns as obtained in a form of EPI-gram. Homeostasis of Prana is operationally defined as uniformity of electro photonic emission patterns in a form of EPI-gram as obtained by EPI instrument. Electron availability is operationally defined as the intensity of electro photonic patterns obtained from EPI-grams.

However, when this homeostasis level of Prana is disturbed, it leads to pain and somatic diseases later as postulated in yoga (Srinivasan 2014; Srinivasan 2013). All the animate beings require steady conditions inside for their survival, such as internal temperature, body $\mathrm{pH}$, metabolic rate and energy expenditure versus energy consumption; similarly, energy (Prana) homeostasis is required for healthy functioning of all systems within the body. The health and disease concept of yoga enables us to better understand the root cause of diseases and disorders (Vyadhi) which are believed to emerge from the disrupted mind (leading to $\underline{A d h i}$ ). The disturbed mind leads to stress and further creates imbalances in Prana, finally manifest as disease or disorder at the physical level (Nagarathna and Nagendra 2009), especially in those systems and organs which have either deficient or disturbed Prana. This understanding of disease manifestation suggests that if this hindrance in energy (Prana) could be prevented or corrected, then we could probably succeed in preventing diseases and also reverse the progress of manifested diseases.

Earlier research on short-term lifestyle modification and stress management education program based on Yoga has shown remarkable improvement in subjective well-being scores of the subjects (Sharma et al. 2008). This could therefore make a considerable contribution to early prevention as well as management of lifestyle diseases. The present evidence convinced us to attempt research on yoga based lifestyle-related program in healthy subjects to prevent ill health and promote health.

Therefore, the present single-arm prospective study was undertaken to study the potential effect of an integrated yoga program on energy parameters, namely; Activation Coefficient (a measure of stress), Integral Area (a measure of general health), and Integral Entropy (a measure of disorderliness) as measured through EPI technique. The study also attempts to find out the reproducibility of EPI outcomes and also to check whether energy outcomes differ gender-wise. 


\section{Material and Methods}

\section{Suhjects}

A total of 152 volunteers were assessed before and after four weeks of a one month Yoga Instructor Course (YIC) at Swami Vivekananda Yoga Anusamdhana Samsthana (S-VYASA, Yoga University), Bengaluru, Karnataka, India. All volunteers were selected from four batches of YIC (Months - May 2014, $n=43$, June 2014, $n=52$, July 2014, $n=38$ and August 2014, $n=19$ ).

\section{Inclusion criteria}

Healthy volunteers, age ranging 18 to 60 years, both male and female, willing to participate in the study and having post hoc Integral Area value between -0.6 to +1 (IA, normal health index range in European Popultion in the EPI technique) were included in the study.

\section{Exclusion criteria}

Volunteers who had cuts in the fingers, missing fingers, having any health-related issues and substance abuse were excluded from the study.

\section{Ethical consideration}

The study protocol was approved by the Institutional Ethics Committee. A written informed consent was obtained from all the volunteers who were willing to participate in the study before the assessment, and the confidentialities of their data and information were maintained.

\section{Yoga intervention}

Residential Integrated Yoga Program (IYP) for four weeks.

The program comprises of Kriya (cleansing techniques), Asana (Physical postures), Pranayama (Breathing practices), Dhyana (meditation), Bhajan (devotional songs), Krida Yoga (Yoga games), spiritual discourses and lectures on yoga and philosophy. The program starts daily at 4.30 am till $10.00 \mathrm{pm}$ and the diet is vegetarian (yogic food).

\section{Assessments}

\section{EPI technique}

Electro Photonic Imaging (EPI) technique also known as Gas Discharge Visualization (GDV) has been used in a number of studies as a scientific device to evaluate stress, general health and disorderliness based on a measure of stimulated optoelectronic emission of humans (Korotkov et al. 2010; Korotkov et al. 2012; Deo et al. 2015; Kushwah et al. 2015).This emission takes place when the finger tips are exposed to a short electric pulse of high voltage $(10 \mathrm{kv})$, with high frequency $(1024 \mathrm{~Hz})$ and low current in micro amps for less than a millisecond (Ciesielska 2009). Emission is captured in the form of an image by a CCD-camera placed under a dielectric plate in the EPI system (Hacker et al. 2005). Further, the acquired 10 EPI images are divided into various sectors, which 
correlate with diverse organs and systems within the body (Korotkov et al. 2012; Hacker et al. 2011; Korotkov 2011) This correlation of EPI image sectors with different organs of the body is mostly based on empirical findings and also supported by both acupuncture and meridian system of Sujok (Korotkov 2002). Recently, meridian system has been scientifically supported by a newly found circulatory system called Bonghan system. It is a thread like structure found on the superficially inside blood or lymph vessels, on the surface of internal organs, and also in the brain ventricles (Soh 2009). It provides a possible connection between the EPI sectors from finger tips' images and with the organs and systems within the body. EPI assessment is done in two ways; namely, with filter and without filter (Korotkov et al. 2012). A filter is a plastic film specially designed to be used in between the finger tips and the dielectric plate to eliminate the sympathetic response which results in sweat and cooling sensations of fingers and to register the information which is more of physiological in nature. Measurements using filter provides physiological and without filter provides psycho-physiological information (Korotkov 2002).

\section{EPI Parameters}

1. Activation Coefficient (AC), 2. Integral Area, left and right side (IAL and IAR) and 3. Integral Entropy, left and right side (IEL and IER).

AC parameter is an estimation of stress level acquired by comparing the reading with and without filter. Hence, it is the difference between sympathetic and parasympathetic responses. It ranges from $0-10$ where $2-4$ is an indication of normal quiescent state. Below 2 - is a state of relaxed and calm people. This could be because of the two possible reasons, deep meditation or chronic depression. AC above 4 indicates exited state and towards higher levels of stress. IA, left and right parameter is a magnitude of general health index of a person being investigated and ranges from $[-0.6$ to +1$]$ and is an indicative of good health condition. IE, left and right parameter is a determinant of disorderliness in the human energy system. A range of [1 to 2] indicates a healthy pattern of entropy in an organism (Korotkov 2002; Cioca et al. 2004; Kostyuk et al. 2011).

Further, the EPI provides a non-invasive, objective and painless method, which is used for quick evaluation of health abnormalities in the human energy system (Korotkov 2011; Korotkov et al. 2010). Therefore, it is gaining high significance in the field of medicine and energy dimensions. From the reliability point of view, EPI parameters have a variation of $4.1 \%$ on a daily average, whereas, on 10 minute average it varies only $6.6 \%$ shows high reliability of the technique (Korotkov 2011). In the present study, EPI Pro and EPI Compact devices, produced by Kirlionics Technologies International, Saint-Petersburg, Russia were used in the assessment processes.

\section{Procedure}

The experiments were carried out four times on four different YIC programs in order to find out the reproducibility of EPI outcomes. All subjects were assessed before and after four weeks of their YIC course. The readings were taken from all 10 fingers in two ways, namely without filter and with filter. In order to obtain a reliable and reproducible data, an established guideline (Alexandrova et al. 2002) was followed. The data was collected after three hours of food intake. The subjects were asked to remove all metallic items which they do not wear for 24 hours in a day. Further, they were also provided an electrically isolated surface to stand on during the measurements and were instructed to place the finger on the dielectric glass plate at $45^{\circ}$ angle. A distance of 3 feet between the EPI camera and the computer system was maintained; the calibration of the instrument was performed routinely, and an alcoholic solution was used to clean the glass plate after the assessment of each individual. 


\section{Temperature and humidity megsurements}

To check the variability in the environmental condition during measurement time, we used a Thermo/ Hygrometer - Equinox, EQ $310 \mathrm{CTH}$. This dimension is necessary to quantify and check as the variation in this environmental factors influence the electro photonic emission pattern, especially if the changes are greater than $\pm 2.5 \%$ (Korotkov 2011). The average temperature observed during all four experiments was (mean $\pm \mathrm{sd}$ ) pre 29.10 $\pm 1.06^{\circ} \mathrm{C}$ and post $29.20 \pm 2.39^{\circ} \mathrm{C}$ and humidity pre $59 \%$ and post $59 \%$.

\section{Data extraction and analysis}

The GDV diagram program was used to extract the raw data from the EPI system into Excel. This program provides all parameters which were taken into consideration for analysis, namely Activation Coefficient, Integral Area and Integral Entropy. Further, data analysis was carried out using ' $R$ statistical package for data analyses' (R Development Core team 2014) and Microsoft Excel program. Paired sample t-test was used for evaluating pre and post readings and independent sample t-test for cross sectional comparisons between male and female subgroups.

\section{Results}

Out of 152 volunteers, a total of 94 healthy subjects (male 55 and female 39, age, mean \pm sd $26.70 \pm 8.58$ ) who were eligible as per the inclusion and exclusion criteria were only considered in the analysis. Table 1 presents the participants' characteristics of subgroups as males and females and as a whole. There is no difference in between the age and BMI of both the genders.

Table 1. Participants' Characteristics

\begin{tabular}{lccc}
\hline \multicolumn{1}{c}{ Variables } & Male $(\mathrm{n}=55)$ & Female $(\mathrm{n}=39)$ & Total $(\mathrm{n}=94)$ \\
\hline Age (year) & $26.93 \pm 9.12$ & $26.36 \pm 7.87$ & $26.70 \pm 8.58$ \\
Height $(\mathrm{cm})$ & $169.16 \pm 9.96$ & $159.31 \pm 6.08$ & $165.07 \pm 8.19$ \\
Weight $(\mathrm{kg})$ & $65.05 \pm 12.99$ & $57.79 \pm 10.12$ & $62.04 \pm 12.36$ \\
BMl $\left(\mathrm{kg} / \mathrm{m}^{2}\right)$ & $22.70 \pm 3.92$ & $22.78 \pm 3.82$ & $22.73 \pm 3.86$ \\
\hline
\end{tabular}

The observations in all four experiments (psycho-physiological level) showed a decreasing trend of AC, increase in IA, left and right and decrease in IE left. Whereas, IE right was found increasing in three of four experiments and decreased only in one experiment. This suggests that there exist a reproducibility of stress reduction and health improvement through Integrated Yoga Practices. Table 2 presents results from all four groups combined into one, where the decrease in AC value turned highly significant $(p<0.001, d=0.59)$. The results at the psycho-physiological level showed a highly significant increase in both IA, left and right (IA left $p<0.001, d=0.39$ and IA right $p<0.001, d=0.48$ ). The IE left values decreased from higher to lower (IE left $1.88 \pm 0.17$, to $1.84 \pm 0.15$, $p=0.07, d=0.18$ ), but not significantly. The mean values of IE right side shifted towards higher, but marginally not significantly (IE right $1.85 \pm 0.24$ to $1.88 \pm 0.17, p=0.30, d=0.1$ ). Whereas, the results at the physiological level were found very stable except IE Left, which showed a shift of a marginal increase within the normal range. 
Table 2. Pre-post changes at both psycho-physiological and physiological levels $(n=94)$

\begin{tabular}{lccccc}
\hline Levels & Variables & $\begin{array}{c}\text { Pre } \\
\text { mean } \pm \mathrm{sd}\end{array}$ & $\begin{array}{c}\text { Post } \\
\text { mean } \pm \mathrm{sd}\end{array}$ & t-value & p-value \\
\hline \multirow{3}{*}{$\begin{array}{l}\text { Without } \\
\text { filter }\end{array}$} & AC & $3.28 \pm 1.21$ & $2.56 \pm 0.60$ & 5.75 & $<0.001^{* * *}$ \\
& IAL & $-0.002 \pm 0.24$ & $0.11 \pm 0.15$ & -3.78 & $<0.001^{* * *}$ \\
& IER & $-0.01 \pm 0.21$ & $0.10 \pm 0.16$ & -4.57 & $<0.001^{* * *}$ \\
& IER & $1.88 \pm 0.17$ & $1.84 \pm 0.15$ & 1.86 & 0.070 \\
\multirow{3}{*}{ With } & IAL & $0.39 \pm 0.16$ & $0.39 \pm 0.12$ & -0.14 & 0.890 \\
filter & IAR & $0.39 \pm 0.15$ & $0.39 \pm 0.13$ & -0.04 & 0.960 \\
& IEL & $1.91 \pm 0.15$ & $1.95 \pm 0.15$ & -1.92 & 0.060 \\
& IER & $1.94 \pm 0.15$ & $1.94 \pm 0.15$ & -0.21 & 0.830 \\
\hline
\end{tabular}

Abbreviations: AC - Activation Coefficient; IAL - Integral Area Left side; IAR - Integral Area Right side; IEL - Integral Entropy Left side; IER - Integral Entropy Right side. Significant level, ${ }^{*} p<0.05,{ }^{* *} p<0.01,{ }^{* * *} p<0.001$.

Tahle 3. Pre and post results of sub groups at both psycho-physiological and physiological levels

\begin{tabular}{|c|c|c|c|c|c|c|c|c|c|}
\hline \multirow[b]{2}{*}{ Levels } & \multirow[b]{2}{*}{ Variables } & Pre male & Post male & \multirow[b]{2}{*}{ t-value } & \multirow[b]{2}{*}{$p$-value } & \multirow{2}{*}{$\begin{array}{c}\text { Pre female } \\
\text { mean } \pm \text { sd } \\
(n=39)\end{array}$} & \multirow{2}{*}{$\begin{array}{c}\text { Post female } \\
\text { mean } \pm \text { sd } \\
(n=39)\end{array}$} & \multirow[b]{2}{*}{ t-value } & \multirow[b]{2}{*}{ p-value } \\
\hline & & $\begin{array}{c}\text { mean } \pm s d \\
(n=55)\end{array}$ & $\begin{array}{c}\text { mean } \pm s d \\
(n=55)\end{array}$ & & & & & & \\
\hline & $A C$ & $3.09 \pm 1.06$ & $2.58 \pm 0.55$ & 3.25 & $0.002^{* *}$ & $3.55 \pm 1.36$ & $2.52 \pm 0.66$ & 5.13 & $<0.001^{* * *}$ \\
\hline \multirow{4}{*}{$\begin{array}{l}\text { Without } \\
\text { filter }\end{array}$} & $\mathrm{IAL}$ & $0.07 \pm 0.19$ & $0.13 \pm 0.13$ & -1.96 & $0.050^{*}$ & $-0.11 \pm 0.25$ & $0.07 \pm 0.16$ & -3.36 & $0.002^{* *}$ \\
\hline & IAR & $0.04 \pm 0.19$ & $0.12 \pm 0.15$ & -2.71 & $0.009^{* *}$ & $-0.08 \pm 0.21$ & $0.08 \pm 0.16$ & -3.78 & $<0.001^{* * *}$ \\
\hline & IEL & $1.88 \pm 0.17$ & $1.83 \pm 0.16$ & 1.66 & 0.100 & $1.88 \pm 0.17$ & $1.85 \pm 0.14$ & 0.90 & 0.370 \\
\hline & IER & $1.85 \pm 0.22$ & $1.90 \pm 0.18$ & -1.10 & 0.270 & $1.84 \pm 0.27$ & $1.85 \pm 0.17$ & -0.27 & 0.790 \\
\hline \multirow{4}{*}{$\begin{array}{l}\text { With } \\
\text { filter }\end{array}$} & IAL & $0.42 \pm 0.13$ & $0.42 \pm 0.11$ & 0.25 & 0.800 & $0.35 \pm 0.20$ & $0.36 \pm 0.13$ & -0.31 & 0.760 \\
\hline & IAR & $0.43 \pm 0.12$ & $0.41 \pm 0.11$ & 0.91 & 0.360 & $0.35 \pm 0.19$ & $0.37 \pm 0.15$ & -0.58 & 0.570 \\
\hline & IEL & $1.92 \pm 0.14$ & $1.95 \pm 0.16$ & -1.19 & 0.240 & $1.89 \pm 0.15$ & $1.95 \pm 0.14$ & -1.53 & 0.130 \\
\hline & IER & $1.96 \pm 0.15$ & $1.91 \pm 0.15$ & 2.35 & $0.020^{*}$ & $1.92 \pm 0.16$ & $1.99 \pm 0.14$ & -2.35 & $0.020^{*}$ \\
\hline
\end{tabular}

Abbreviations: AC - Activation Coefficient; IAL - Integral Area Left; IAR - Integral Area Right; IEL - Integral Entropy Left side; IER - Integral Entropy Right side. Significant level, ${ }^{*} p<0.05,{ }^{* *} p<0.01,{ }^{* * *} p<0.001$.

Both groups demonstrated significant reduction in stress levels and significant improvement in general health index after IYP at the psycho-physiological level. However, integral entropy parameter at (NF) level did not show any change. At physiological level, IE right side decreased significantly in the male group, whereas it significantly increased in the female group. Other parameters at the physiological level in both the groups did not reveal significant changes.

The baseline comparisons between both groups showed higher mean values of $A C$ in females than males (AC, females $3.55 \pm 1.36$ and males $3.09 \pm 1.06, p=0.06$ ). The magnitude of mean values of $I A$, left and IA right side (NF) readings were found significantly higher in males (IA left $p<0.001$ and IA right $p<0.01$ ) than females, whereas, no significant difference was found from IE left and IE right values between the groups. Further, the magnitude of IA left and IA right values (WF) were significantly higher in males than females (IA left $p=0.04$ and IA right $p=0.02$ ). However, no significant difference was found from IE left and IE right (WF) in between the genders. 
Tahle 4. Cross sectional results (between males and females) at both psycho-physiological and physiological levels

\begin{tabular}{|c|c|c|c|c|c|c|c|c|c|}
\hline \multirow[b]{2}{*}{ Levels } & \multirow[b]{2}{*}{ Variables } & \multirow{2}{*}{$\begin{array}{c}\text { Pre male } \\
\text { mean } \pm \text { sd } \\
(n=55)\end{array}$} & \multirow{2}{*}{$\begin{array}{c}\text { Pre female } \\
\text { mean } \pm \text { sd } \\
(n=39)\end{array}$} & \multirow[b]{2}{*}{ t-value } & \multirow[b]{2}{*}{$p$-value } & \multirow{2}{*}{$\begin{array}{l}\text { Post male } \\
\text { mean } \pm \text { sd } \\
(n=55)\end{array}$} & \multirow{2}{*}{$\begin{array}{c}\text { Post female } \\
\text { mean } \pm \text { sd } \\
(n=39)\end{array}$} & \multirow[b]{2}{*}{ t-value } & \multirow[b]{2}{*}{ p-value } \\
\hline & & & & & & & & & \\
\hline & $A C$ & $3.09 \pm 1.06$ & $3.55 \pm 1.36$ & 1.88 & 0.060 & $2.58 \pm 0.55$ & $2.52 \pm 0.66$ & -0.47 & 0.640 \\
\hline \multirow{4}{*}{$\begin{array}{l}\text { Without } \\
\text { filter }\end{array}$} & IAL & $0.07 \pm 0.19$ & $-0.11 \pm 0.25$ & -3.67 & $<0.001^{* * *}$ & $0.13 \pm 0.13$ & $0.07 \pm 0.16$ & -2.06 & $0.040^{*}$ \\
\hline & IAR & $0.04 \pm 0.19$ & $-0.08 \pm 0.21$ & -2.93 & $<0.010^{* *}$ & $0.12 \pm 0.15$ & $0.08 \pm 0.16$ & -1.26 & 0.210 \\
\hline & IEL & $1.88 \pm 0.17$ & $1.88 \pm 0.17$ & -0.12 & 0.900 & $1.83 \pm 0.16$ & $1.85 \pm 0.14$ & 0.36 & 0.720 \\
\hline & IER & $1.85 \pm 0.22$ & $1.84 \pm 0.27$ & -0.24 & 0.810 & $1.90 \pm 0.18$ & $1.85 \pm 0.17$ & -1.29 & 0.200 \\
\hline \multirow{4}{*}{$\begin{array}{l}\text { With } \\
\text { filter }\end{array}$} & IAL & $0.42 \pm 0.13$ & $0.35 \pm 0.20$ & -2.10 & $0.040^{*}$ & $0.42 \pm 0.11$ & $0.36 \pm 0.13$ & -2.28 & $0.020^{*}$ \\
\hline & IAR & $0.43 \pm 0.12$ & $0.35 \pm 0.19$ & -2.38 & $0.020^{*}$ & $0.41 \pm 0.11$ & $0.37 \pm 0.15$ & -1.66 & 0.100 \\
\hline & IEL & $1.92 \pm 0.14$ & $1.89 \pm 0.15$ & -0.78 & 0.440 & $1.95 \pm 0.16$ & $1.95 \pm 0.14$ & -0.11 & 0.910 \\
\hline & IER & $1.96 \pm 0.15$ & $1.92 \pm 0.16$ & -1.23 & 0.220 & $1.91 \pm 0.15$ & $1.99 \pm 0.14$ & 2.90 & $0.005^{\star *}$ \\
\hline
\end{tabular}

Abbreviations: AC - Activation Coefficient; IAL - Integral Area Left; IAR - Integral Area Right; IEL - Integral Entropy Left side; IER - Integral Entropy Right side. Significant level, ${ }^{*} p<0.05,{ }^{* *} p<0.01,{ }^{* * *} p<0.001$.

Post of male and female data indicated improvement in all parameters except IE right (WF), which showed a significant shift towards higher values in the females group, though this increase was in the normal range of the entropy parameter.

\section{Discussion}

Compared with the previous research in the field of yoga, the present study is first of its kind to measure the effect of Integrated Yoga Program (IYP) on healthy volunteers, makes an attempt to find out whether EPI parameters differ gender-wise and tries to establish the reproducibility of the EPI outcomes by conducting four different experiments.

The results from all four experiments (psycho-physiological level) were found reproducible except for IE right side which exceptionally increased in three of four experiments. There was a highly significant decrease in activation coefficient and highly significant improvement in integral area, left and right side (psycho-physiological level) after four weeks of IYP. Similar changes were also observed from subgroups of male and female. Further, the baseline comparisons between the genders have also demonstrated the significant difference in IA, left and right side from both without filter and with filter readings.

\section{Psycho-physiological level}

\section{Activation coefficient (stress parameter)}

A number of studies have evidence of the phenomenon that regular practice of integrated yoga reduces stress in various populations (Buffart et al. 2012; McDermott et al. 2014; Michalsen 2008; Rao et al. 2008; Yoshihara et al. 2014). The results from the present study also show that integrated yoga practice on a regular basis reduces stress significantly $(p<0.001)$ in healthy people. This may be due to the yoga practices which work on autonomic nervous system (Streeter 2012) and restore balance between sympathetic and parasympathetic responses. Development of a coherence zone between both SNS and PNS responses may regulate, unify and correct the imbalances in the flow of Prana in the body. This may be confirmed by the uniformity throughout the EPI image glow area which increases 
after the yoga practice. Earlier, this phenomenon was noticed in a pilot study by other researchers. It was found that during progression of relaxation, the sensitive stress marker Salivary Alpha Amylase (sAA) (Van Stegeren 2006) decreased, whereas, the EPI image glow area increased (Hacker 2011). It suggests that significant reduction in AC leads to prevention of any abnormality in the Pranic energy distribution which could lead to prevention of diseases.

\section{Integral Area (IA, general healith index)}

It is well known that yoga components, i.e., physical postures, breathing techniques, meditation, cleansing techniques, and diet practices improve health and well-being in individuals (Jagannathan et al. 2014; Cabral et al. 2011; Gomes-Neto et al. 2014; Buffart et al. 2012). The present study also showed a highly significant increase in IA left $(p<0.001)$ and right $(p<0.001)$ which suggest improvement in general health of the participants. It may be due to reduction in stress level leading towards harmony and improved Pranic circulation, indicating improvement in psycho-physiological health.

\section{Integlal Entropy (IE, disorderliness)}

The integrated practices of yoga improve and regulate the vital energy called Prana (Sharma et al. 2014). Keeping harmonious homeostasis of this energy is a key essence of yoga practice, which keeps one healthy and promotes positive health (Nagarathna and Nagendra 2009). Loss of homeostasis of the energy produces entropy, which is otherwise known as disorderliness in the human energy systems (Korotkov 2002) and high or low entropy may lead to diseases in the body. The shift of IE left higher to lower values and IE right toward higher may be an adjustment towards balance in both. It indicates better energy homeostasis through IYP, which is an indication of prevention of ill health.

\section{Physiological level}

Present study results at the physiological level have demonstrated the strength of regular practice of yoga, which helps in sustaining the homeostasis level of energy by keeping both mind and body in harmony. That is a unique outcome from the study suggesting that yoga is a boon for the health. The finding showed that the mean values of IA left, right and IE right was same before and after the IYP. Although, the IE left showed a shift of an increase within the normal range, but was negligible and not significant.

\section{Gender-wise comparisons}

Subgroup analysis of males and females showed a clear significant difference of energy parameters at the baseline. One of the previous studies reported that women experience more stress than men (Matud 2004). The findings of our present study are also similar, showing that magnitude of the stress parameter is higher in females than males as found from the baseline comparisons of both males and females. After the intervention, both male and female groups showed a significant reduction in stress level. It is a well-known fact that high-stress levels affect the health of individuals. According to a report by American Psychological Association, women are more prone to the stress-related health problems such as hypertension, depression, anxiety, and obesity (Herscher 2014) than men. The present study findings showed significantly lower level of the IA values in females than males at both physiological and psycho-physiological levels in baseline comparison. This suggests that females are more 
susceptible to develop health issues than males. After the IYP, IA values showed significant improvement in both the groups, but the magnitude of improvement was more in females than males as compared with pre scores. Studies have reported that socio economic and cultural factors influence the health of females, whereas the work responsibilities influence males (Annette 2001; American Psychological Associantion 2015). Baseline comparisons of the IE, left and right values at both psycho-physiological and physiological levels indicated no difference between males and females. However, after the intervention IE right side (WF) decreased significantly in the male group indicating reduction in disorderliness, whereas, an exception of significant increase was observed in IE right values in the female group, but it was within the normal range. Moreover, these findings suggest that gender has an influence on energy patterns which needs to be studied separately with more data to substantiate the findings.

\section{Strength}

The findings of reproducible EPI outcomes, highly significant reduction in stress, highly significant improvement in general health indices (psycho-physiological level) and the baseline comparisons of males and females, which showed significant difference in general health indices (psycho-physiological and physiological level) provide the strength for the study.

\section{Limitations}

Absence of a control group may have posed a threat to the internal validity of the study; however, we estimate that this would at the maximum obscure the measured magnitude of the effects but not the direction of effect. A further confirmatory study may be done to better estimate the effect sizes.

\section{Suggestions for future study and Implication of the study}

From the findings of significant difference in energy trend between the males and females, it is suggested that males and females should be studied separately. Further, it is also suggested that future study should attempt to follow the subjects after the completion of study in order to find out prolonging effects of yoga practices. Moreover, IYP can be implemented for the prevention of ill health and promotion of health in individuals.

\section{Conclusions}

Present study achieved the reproducible results of stress, general health and disorderliness parameters in all four experiments at the psycho-physiological level except IE right side. Outcomes of the study also suggest that the energy parameters differ gender-wise and hence needs to be studied separately with more data to substantiate the findings. Further, the findings from the investigations also suggest that IYP can be used to regulate, improve and sustain the energy homeostasis of an organism. This, in essence, is important in the field of prevention and sustenance of health.

\section{Acknowledgments}

The authors would like to thank Dr. Judu V. Ilavarasu $(\mathrm{PhD})$ for reviewing the draft and Mr. Guru Deo (PhD scholar), Dr. Padamavati Maharana (PhD), Dr. T. Indira Rao (PhD), and Mr. Kuntal Ghosh (PhD Scholar) for their consistent assistance in data collection. 


\section{References}

Alexandrova R., Fedoseev G., Korotkov K.G., Philippova N., Zayzev S., Magidov M., Petrovsky I. Analysis of the Bioelectrograms of Bronchial Asthma Patients. In: Korotkov KG, editor. HumanEnergy Field: Study with GDV bioelectrography. Fair Lawn: Backbone Publishing Co. 2002: 92-102.

American Psychological Association. Stress on the Rise for Women. 2015, www.apa.org/news/press/releases/stress/2010/genderstress.aspx.

Bijlani R.L., Vempati R.P., Yadav R.K., Ray R.B., Gupta V., Sharma R., Mehta, N., Mahapatra, S.C. A Brief but Comprehensive Lifestyle Education Program Based and Diabetes Mellitus. J Altern Complement Med. 2005; 11 (2): 267-274.

Buffart L.M., van Uffelen J.G.Z., Riphagen I.I., Brug J., van Mechelen W., Brown W.J., Chinapaw, M.J. Physical and psychosocial benefits of yoga in cancer patients and survivors, a systematic review and meta-analysis of randomized controlled trials. BMC Cancer. 2012; 12 (1): 559.

Cabral P., Meyer H.B., Ames D. Effectiveness of Yoga Therapy as a Complementary Treatment for Major Psychiatric Disorders. Prim Care Companion CNS Disord. 2011; 13 (4). PCC.10r01068.

Ciesielska I.L. Images of corona discharges as a source of information about the influence of textiles on humans. AUTEX Res J. 2009 9 (March).

Cioca G.H., Giacomoni P., Rein G. Correlation between GDV and heart rate variability measures: A new measure of well-being. In: Measuring Energy Fields, ed. K.G. Korotkov. Fair Lawn: Backbone Publishing Co; 2004: 59-64.

Deo G., Itagi R.K., Thaiyar M.S., Kuldeep K.K. Effect of anapanasati meditation technique through electrophotonic imaging parameters: A pilot study. Int J Yoga. 2015; 8: 117-121.

Gard T., Noggle J.J., Park C.L., Vago D.R., Wilson A. Potential self-regulatory mechanisms of yoga for psychological health. Front Hum Neurosci. 2014; 8 (September): 1-20.

Gomes-Neto M., Rodrigues jr. E.S., Silva jr. W.M., Carvalho V.O. Review Article Effects of Yoga in Patients with Chronic Heart Failure : A Meta-Analysis. Arq Bras Cardiol. 2014; 103 (5): 433-439.

Hacker G.W., Pawlak E., Pauser G., Tichy G., Jell H., Posch G., Kraibacher, G., Aigner, A., Hutter, J. Biomedical evidence of influence of geopathic zones on the human body: scientifically traceable effects and ways of harmonization. Forsch Komplementarmed Klass Naturheilkd. 2005; 12 (6): 315-327.

Hacker G.W., Augner C., Pauser G. Daytime-related rhythmicity of gdv parameter glow image area: time course and comparison to biochemical parameters measured in saliva. In: Energy Fields Electrophotonic Analysis in Humans and Nature, ed. K.G. Korotkov. 2011.

Herscher E. Gender and Stress [Internet]. Heal. day news Heal. Living. 2014, http://consumer.healthday.com/encyclopedia/men-shealth-28/men-s-problems-health-news-469/gender-and-stress-645980.html.

Jagannathan A., Nagarathna R., Ramakrsihna J., Villacres M.D. Decoding the integrated approach to yoga therapy: Qualitative evidence based conceptual framework. Int J Yoga. 2014; 7 (1): 22-31.

Korotkov K.G. Human Energy Field: Study with GDV bioelectrography. Fair Lawn: Backbone Publishing Co. 2002.

Korotkov K.G., Matravers P., Orlov D.V., Williams B.O. Application of electrophoton capture (EPC) analysis based on gas discharge visualization (GDV) technique in medicine: a systematic review. J Altern Complement Med. 2010; 16 (1): 13-25.

Korotkov K.G. Energy Fields Electrophotonic Analysis in Humans and Nature. Saint-Petersburg: Amazon.com Publishing. 2011.

Korotkov K.G., Shelkov O., Shevtsov A., Mohov D., Paoletti S., Mirosnichenko D., Labkovskaya E., Robertson, L. Stress reduction with osteopathy assessed with GDV electrophotonic imaging: effects of osteopathy treatment. J Altern Complement Med. 2012; 18 (3): 251-257.

Kostyuk N., Cole P., Meghanathan N., Isokpehi R.D., Cohly H.H.P. Gas discharge visualization: an imaging and modeling tool for medical biometrics. Int J Biomed Imaging. 2011; 2011: 196460.

Kushwah K.K., Srinivasan T.M., Nagendra H.R., Ilavarasu J.V. Effect of yoga based technique on stress and health indices using electro photonic imaging technique in managers. J Ayurveda Integr Med. 2015. In press.

Lynton H., Kligler B., Shiflett S. Yoga in stroke rehabilitation: a systematic review and results of a pilot study. Top Stroke Rehabil. 2007; 14 (4): $1-8$.

Matud M.P. Gender differences in stress and coping styles. Pers Individ Dif. 2004; 37 (7): 1401-1415.

McDermott K.A., Rao M.R., Nagarathna R., Murphy E.J., Burke A., Nagendra R.H., Hecht F.M. A yoga intervention for type 2 diabetes risk reduction: a pilot randomized controlled trial. BMC Complement Altern Med 2014; 14 (1): 212. 
Michalsen A., Jeitler M., Brunnhuber S., Lüdtke R., Büssing A., Musial F., Dobos, G., Kessler, K. lyengar yoga for distressed women: A 3-armed randomized controlled trial. Evidence-based Complement Altern Med. 2012.

Nagarathna R., Nagendra H.R. Integrated Approach Yoga Therapy for Positive Health. Swami Vivekananda Yoga Prakashana. 2009. R Development Core team. A language and environment for statistical computing. 2014, www.r-project.org.

Rao R.M., Nagendra H.R., Raghuram N., Vinay C., Chandrashekara S., Gopinath K.S., Srinath, B.S. Influence of yoga on mood states, distress, quality of life and immune outcomes in early stage breast cancer patients undergoing surgery. Int J Yoga. $2008 ; 1$ (1): $11-20$.

Sancier K.M., Hu B. Medical applications of qigong and emitted qi on humans, animals,cell cultures, and plants. Am J Acupunct. 1991; 19 (4): 367-377.

Segasothy M., Phillips P.A. Vegetarian diet: panacea for modern lifestyle diseases? QJM. 1999; 92: 531-544.

Sharma R., Gupta N., Bijlani R.L. Effect of yoga based lifestyle intervention on subjective well-being. Indian J Physiol Pharmacol. 2008; 52 (2): 123-131.

Sharma B., Hankey A., Nagilla N., Meenakshy K.B., Nagendra H.R. Can yoga practices benefit health by improving organism regulation? Evidence from electrodermal measures of acupuncture meridians. Int J Yoga. 2014; 7 (1): 32-40.

Sharma M., Majumdar P.K. Occupational lifestyle diseases: An emerging issue. Indian J Occup Environ Med. $2009 ; 13$ (3): $109-112$.

Sivananda S.S. The Bhagavad gita. 12th ed. Tehri-Garhwal: The Divine Life Society. 2008.

Smaldone A, Honig J.C., Byrne M.W. Sleepless in America: inadequate sleep and relationships to health and well-being of our nation's children. Pediatrics. 2007; 119 Suppl (February): 29-37.

Soh K.S. Bonghan Circulatory System as an Extension of Acupuncture Meridians. J Acupunct Meridian Stud. 2009 ; 2 (2): 93-106.

Srinivasan T.M. Bridging the mind-body divide. Int J Yoga. 2013; 6 (2): 85-86.

Srinivasan T.M. Prana and electrons in health and beyond. Int J Yoga. 2014; 7 (1): 1-3.

Stanton A.L., Gender, stress and health. Am. Psychol. Assoc. 2001, www.apa.org/monitor/dec01/genderhealth.aspx.

Streeter C.C., Gerbarg P.L., Saper R.B., Ciraulo D.A., Brown R.P. Effects of yoga on the autonomic nervous system, gammaaminobutyric-acid, and allostasis in epilepsy, depression, and $\quad$ post-traumatic stress disorder. Med Hypotheses. 2012; 78 (5): 571-579.

Szent-Gyorgyi A. "The Living State", Marcel Decker, NY, USA, 1978, p. 18.

Van Nieuwenhuizen A.J., Buffart L.M., Brug J., René Leemans C., Verdonck-de Leeuw I.M. The association between health related quality of life and survival in patients with head and neck cancer: A systematic review. Oral Oncol. $2015 ; 51$ (1): 1-11.

Van Stegeren A., Rohleder N., Everaerd W., Wolf O.T. Salivary alpha amylase as marker for adrenergic activity during stress: effect of betablockade. Psychoneuroendocrinology. 2006; 31 (1): 137-141.

Waxman A. Nutrition and Fitness. World Rev Nutr Diet. 2005; 95: 229.

Yoshihara K., Hiramoto T., Oka T., Kubo C., Sudo N. Effect of 12 weeks of yoga training on the somatization, psychological symptoms, and stress-related biomarkers of healthy women. Biopsychosoc Med. 2014; 8 (1): 1-9.

Cite this article aS: Kushwah K.K., Nagendra H.R., Srinivasan T.M. Effect of Integrated Yoga Program on Energy Outcomes as a Measure of Preventive Health Care in Healthy People. Central European Journal of Sport Sciences and Medicine. 2015; 12 (4): $61-71$. 
